\title{
Dietary patterns extracted from the current Japanese diet and their associations with sodium and potassium intakes estimated by repeated $24 \mathrm{~h}$ urine collection
}

\author{
Aya Fujiwara ${ }^{1}$, Keiko Asakura ${ }^{1,2}$, Ken Uechi $^{1}$, Shizuko Masayasu ${ }^{3}$ and Satoshi Sasaki ${ }^{1, *}$ \\ ${ }^{1}$ Department of Social and Preventive Epidemiology, School of Public Health, Graduate School of Medicine, \\ The University of Tokyo, Hongo 7-3-1, Bunkyo-ku, Tokyo 1 13-0033, Japan: ${ }^{2}$ Interfaculty Initiative in Information \\ Studies, The University of Tokyo, Tokyo, Japan: ${ }^{3}$ Ikurien-naka, Ibaraki, Japan
}

Submitted 18 October 2015: Final revision received 17 February 2016: Accepted 3 March 2016: First published online 6 April 2016

\begin{abstract}
Objective: To identify dietary patterns in the current Japanese diet and evaluate the associations between these patterns and $\mathrm{Na}$ and $\mathrm{K}$ intakes.

Design: Dietary patterns were extracted by factor analysis from the intakes of food groups assessed with a validated self-administrated diet history questionnaire. $\mathrm{Na}$ and $\mathrm{K}$ intakes and urinary $\mathrm{Na}: \mathrm{K}$ were assessed by repeated $24 \mathrm{~h}$ urine collection.

Subjects: Healthy Japanese adults aged 20-69 years (353 men and 349 women). Setting: Twenty study areas in twenty-three prefectures in Japan.

Result: Four dietary patterns were identified in each sex. After adjustment for several confounding factors, the 'Fish and vegetable' pattern was associated with higher urinary $\mathrm{Na}$ excretion, but the association was not significant $(P=0.37$ in men and $P=0.06$ in women). This pattern was also associated with higher $\mathrm{K}$ excretion in both sexes. The 'Noodle' pattern tended to be associated with higher urinary $\mathrm{Na}$ excretion $(P=0.17$ in men and $P=0.04$ in women $)$ and higher $\mathrm{Na}: \mathrm{K}(P=0.02$ in men). The 'Meat, vegetable and oil' (in men)/'Meat and oil' (in women) and 'Bread and confectioneries' patterns were not associated with urinary $\mathrm{Na}$ excretion (in men) or were negatively associated (in women).

Conclusions: Contrary to the case in Western countries, the 'Fish and vegetable' and 'Noodle' patterns contributed to higher Na intake in Japan. Target foods for salt reduction should be set based on careful consideration of the relationships between dietary patterns and $\mathrm{Na}$ and $\mathrm{K}$ intakes in the target population.
\end{abstract}

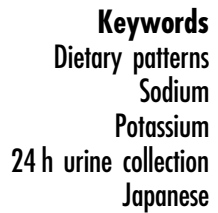

Excess $\mathrm{Na}$ intake and insufficient $\mathrm{K}$ intake are well-known risk factors for hypertension and $\mathrm{CVD}^{(1)}$. Since salt reduction is one of the most cost-effective means of reducing noncommunicable diseases such as $\mathrm{CVD}^{(2)}$, population salt reduction programmes have been developed worldwide ${ }^{(3,4)}$. To promote these programmes effectively, the WHO recommends the evaluation and monitoring of $\mathrm{Na}$ consumption in each population and sources of $\mathrm{Na}$ in the $\operatorname{diet}^{(5)}$.

East Asian countries, including Japan, have higher $\mathrm{Na}$ intake and lower $\mathrm{K}$ intake than other countries ${ }^{(6,7)}$. Using precise assessment by $24 \mathrm{~h}$ urine collection $^{(8)}$, we recently showed that the average intake of $\mathrm{Na}$ in Japan was still high and that of $\mathrm{K}$ was $\mathrm{low}^{(9)}$, and that many people did not meet the WHO recommendation ${ }^{(10,11)}$. High salt consumption from traditional Japanese seasonings and processed foods, such as soya sauce, miso (fermented soyabean paste), pickled vegetables and fish (including sea products), is considered to be the downside of the
Japanese diet ${ }^{(12,13)}$. Given the difference between the Japanese diet and the Western diet, with the latter including bread and meat products as major contributors to $\mathrm{Na}$ intake ${ }^{(3,12)}$, Japanese populations require a different salt reduction strategy. Since the dietary pattern approach can extract a number of different consumption patterns from overall diets in an analysed population ${ }^{(14)}$, this approach might clarify the difference in intake styles between the Japanese and Western diets and show what aspects of the current Japanese diet are associated with higher salt consumption.

The association between dietary patterns and $\mathrm{Na}$ intake has been investigated in Japanese people ${ }^{(15-19)}$, but these studies estimated $\mathrm{Na}$ intake by dietary assessment questionnaires in which measurement error cannot be ignored $^{(20,21)}$. To date, only one British study has investigated the association between dietary patterns and $\mathrm{Na}$ intake using 24 h urinary collection ${ }^{(22)}$, and no comparable research from Asian countries has yet appeared, including Japan. 
In the present study, we identified dietary patterns in the current Japanese diet and evaluated the associations between these patterns and $\mathrm{Na}$ and $\mathrm{K}$ intakes measured by repeated $24 \mathrm{~h}$ urine collection.

\section{Methods}

\section{Study participants}

Details of the study design and procedure have been described elsewhere ${ }^{(9)}$. Briefly, the study was based on data from a cross-sectional multicentre survey, conducted in February or March 2013, among healthy welfare facility staff aged 20-69 years from 199 facilities in twenty study areas in twenty-three prefectures in Japan. First, 199 dietitians working in these facilities were recruited to support the study as research dietitians. These dietitians recruited their co-workers as participants. They were not selected randomly but were volunteers. Exclusion criteria were: (i) licensed dietary or medical provider (e.g. dietitian, nurse or medical doctor); (ii) residence in the prefecture or prefecture adjacent to that in which the facility was located (workplace at the time of the study) commencing after 1 August 2012; (iii) under diet therapy prescribed by a doctor or dietitian at the time of the study or within 1 year before the study; (iv) pregnant or lactating women; and (v) history of educational admission for diabetes mellitus. In total, 791 individuals $(395$ men and 396 women) participated in the survey. Written informed consent was obtained from all participants.

\section{Measurement schedule}

All measurements were made in February or March 2013. Main examination items were semi-weighed diet records (DR; obtained from 392 participants), $24 \mathrm{~h}$ urine collection (two non-consecutive days), three questionnaires (two types of diet history questionnaire and one lifestyle questionnaire) and anthropometric measurements (body height and weight). First, four non-consecutive survey days for the DR were arranged. Then, two $24 \mathrm{~h}$ urine collections were planned before and after the four DR days. The questionnaire surveys were performed between the first urine collection and the first DR. The measurement schedule aimed to complete all measurements within 10 to $14 \mathrm{~d}$ and was arranged by the research dietitian and the participant him- or herself in consideration of the participant's work and private schedules.

\section{Dietary assessment and food grouping}

Dietary habits during the preceding month were assessed using a validated, self-administered diet history questionnaire (DHQ $)^{(23-25)}$. Estimates of daily intake for 151 food and beverage items, energy and nutrients were calculated using an ad hoc computer algorithm for the DHQ, which was based on the Standard Tables of Food Composition in Japan ${ }^{(26)}$. For most items, the intakes were calculated based on the reported consumption frequency and portion size according to the semi-quantitative food frequency methodology. For seasonings used during cooking, the intakes were estimated according to the diet history method, using the qualitative and quantitative information (i.e. cooking method and frequency of the intake). Responses to the DHQ were checked at least twice for completeness, and when necessary were reviewed with the participants by trained survey staff (mostly dietitians) to ensure the accuracy and clarity of answers. After the exclusion of four items (nutritional supplement bars, artificial sweeteners, energy drinks and drinking-water), 147 food items in the DHQ were grouped into forty-one predefined food groups by adding food items within each group (see online supplementary material, Supplemental Table 1) to extract dietary patterns. We excluded the former three items because nutrient contents of these items were unclear, and the number of participants who consumed these items and the amount of intake were small in the present study. Similarly, drinkingwater was excluded because accurate estimation for its intake by DHQ was thought to be difficult. Grouping was defined according to the culinary usage of the food items and the similarity of nutrient profiles, with some modification from a previous report ${ }^{(27)}$ to ensure that the purposes of the present study were met. In this step, we particularly considered the Na content in each food. The following food groups in the previous report ${ }^{(27)}$ were separated due to the difference in $\mathrm{Na}$ content: 'Confectioneries' was separated into 'Sweetened bun', 'Confectioneries (i.e. sweets)' and 'Savoury snacks'; 'Dairy products' was separated into 'Cheese' and 'Milk and yoghurt'; and 'Sea products' was separated into 'Salty sea products' (sea products including more than $4 \mathrm{~g}$ salt per $100 \mathrm{~g}$ of edible portion, such as salted fish eggs, boiled fish in soya sauce and salted fish guts) and 'Sea products' (other sea products). We also composed 'Salt', 'Japanese seasonings' and 'Western seasonings' groups from 'Salt-containing seasonings' and a part of 'Pulses (miso)' and 'Vegetable oils (salad dressings with oil and mayonnaise) ${ }^{,(27)}$ (Supplemental Table 1).

\section{Twenty-four-bour urine collection}

Twenty-four-hour urine collection was performed twice on two non-consecutive days during the study period to measure $\mathrm{Na}$ and $\mathrm{K}$ excretion. A detailed description of the procedure for $24 \mathrm{~h}$ urine collection has been published elsewhere $^{(9)}$. Briefly, participants were asked to collect all urine voided during a $24 \mathrm{~h}$ period and to record the time of the start and end of the collection period. They were also asked to estimate the volume of any missing urine specimens. The $24 \mathrm{~h}$ urine volume was adjusted by the selfreported collection time of the start and end of the collection period and missing urine volume. This adjustment method has been validated using the $p$-aminobenzoic acid check $\operatorname{method}^{(28)}$. Samples of collected urine were transferred to 
LSI Medicine Corporation (Tokyo, Japan) and analysed for urinary $\mathrm{Na}$ and $\mathrm{K}$ concentration using the electrode method. Creatinine levels were analysed by the enzyme test. A JCA-BM6050 clinical chemistry analyser (JEOL Limited) was used to determine the concentrations of $\mathrm{Na}, \mathrm{K}$ and creatinine. An IatroQ CRE(A) II chemical reagent kit (LSI Medicine Corporation) was also used to determine the concentration of creatinine. Excretion of $\mathrm{Na}$ and $\mathrm{K}$ was calculated as: total $24 \mathrm{~h}$ excretion $(\mathrm{mmol} / \mathrm{d})=$ adjusted volume of $24 \mathrm{~h}$ urine $(\mathrm{ml} / \mathrm{d}) \times$ concentration $(\mathrm{mmol} / \mathrm{ml})$. Na:K was calculated by dividing excreted $\mathrm{Na}(\mathrm{mg} / \mathrm{d})$ by $\mathrm{K}(\mathrm{mg} / \mathrm{d})$. This differs from the Na:K ratio recommended by WHO of 1.0 which is a molar ratio ${ }^{(10)}$. We have therefore not compared our values with the WHO recommendation in the present paper.

\section{Other measurements}

Body height and weight were measured to the nearest $0.1 \mathrm{~cm}$ and $0.1 \mathrm{~kg}$, respectively, with the participant wearing light clothing and no shoes, by the research dietitians or medical staff in the welfare facilities. BMI was calculated as body weight divided by the square of body height $\left(\mathrm{kg} / \mathrm{m}^{2}\right)$. Blood pressure was then measured twice by research dietitians, nurses or the participants themselves using sphygmomanometers in the welfare facilities. The average of the two measurements was used as the participant's representative blood pressure value ${ }^{(29)}$. Information on participant background and lifestyle was collected by a questionnaire, which included twenty-one questions about the participant's occupation, family structure, education, smoking habit, medical history, current medication use and physical activity level (estimated by summing the products of exercise duration and the metabolic equivalent of task (MET) value for each activity $^{(30)}$ ).

\section{Statistical analysis}

All analyses were performed using the statistical software package SAS version 9.4. We analysed men and women separately, because differences in dietary pattern between sexes were reported previously ${ }^{(31)}$. For analysis, we selected 760 participants (384 men and 376 women) whose $24 \mathrm{~h}$ urine collection was considered to be completed at least once, as assessed by calculating the ratio of observed to expected creatinine excretion according to the equation of Jossens et al. ${ }^{(28,32)}$. If the observed creatinine excretion of a urine collection was within 60 to $140 \%$ of the expected value, the collection was considered to be successful ${ }^{(28,32)}$. When both collections were considered successful, the average of the two excretion values of urine collection was used as representative; when only one collection was considered successful, its value was used as representative. We then excluded those who did not answer the DHQ ( $n$ 1). We also excluded participants with severe under- or over-reporting for energy intake as follows: participants with reported energy intake less than half the energy requirement for the lowest physical activity category according to the Dietary Reference Intakes for Japanese, $2015^{(33)}$ or participants with reported energy intake equal to or more than 1.5 times the energy requirement for the highest physical activity category, respectively ( $n$ 12). We further excluded participants who were currently receiving dietary counselling from a doctor or dietitian ( $n$ 45). Finally, the total number of individuals in the analysis was 353 men and 349 women.

Factor analysis to derive dietary patterns based on the forty-one predefined food groups was conducted using the FACTOR PROCEDURE function of the SAS software. Intakes of these food groups $(\mathrm{g} / \mathrm{d})$ were examined by the DHQ, log-transformed to achieve normality and then adjusted for total energy intake by the residual method ${ }^{(8)}$. The factors were rotated by orthogonal transformation (Varimax rotation function in SAS) to achieve a simpler structure with greater interpretability. The number of factors was determined by the eigenvalue $(>1 \cdot 0)$, scree plots and the interpretability of the combination of food groups on the factors. A factor solution with four factors was found to be reasonable and meaningful for both men and women (see online supplementary material, Supplemental Table 2). The proportion of variance explained by each factor was calculated by dividing the sum of the square of the respective factor loading by the number of variables. The factor scores of each dietary pattern for each participant were calculated by summing the intakes of food groups weighted by their factor score loadings. The validity of dietary patterns derived from the DHQ has been reported previously ${ }^{(27)}$.

The factor score for each dietary pattern was categorized into quintiles and general characteristics were compared between these categories. The Mantel-Haenszel $\chi^{2}$ test was used for categorical variables. For continuous variables, a linear regression analysis was conducted to assess trend associations, using factor scores (continuous) as independent variables. To investigate associations between factor scores (quintiles) for dietary patterns and urinary $\mathrm{Na}$ and $\mathrm{K}$ excretions and $\mathrm{Na}: \mathrm{K}$, multivariate-adjusted means of $\mathrm{Na}$ and $\mathrm{K}$ excretion in each quintile were calculated by adjusting for age and weight (model 1). We further adjusted for residential block (six categories), education (high school or less and other, some college, university or more) and smoking (never, past and current) in model 2. Regarding $\mathrm{Na} K$, multivariate-adjusted means were calculated by adjusting for age (model 3) and further adjusting for residual block, education and smoking (model 4), respectively. Trends of association in factor score quintiles were assessed by a linear regression model which included $\mathrm{Na}$ and $\mathrm{K}$ excretions or $\mathrm{Na}: \mathrm{K}$ as a dependent variable and factor scores (continuous), age, body weight, residential block, education and smoking as independent variables. Energy-adjusted mean by the residual method of food group intake and $\mathrm{Na}$ intake from each food group, and its contribution as $\mathrm{Na}$ source to total $\mathrm{Na}$ intake in participants of the highest 
quintile, were calculated for each dietary pattern to show key foods which characterize $\mathrm{Na}$ intake in each dietary pattern. A two-sided $P$ value of $<0.05$ was considered statistically significant.

\section{Results}

In factor analysis, four factors were extracted for each sex and labelled according to those food groups with high loadings (see online supplementary material, Supplemental Table 2). For men, factors were labelled 'Fish and vegetable' (high positive loadings on fish, sea products (e.g. dried fish, canned tuna and fish paste products), green and yellow vegetables, fruits, other vegetables, etc.), 'Meat, vegetable and oil' (positive loadings on vegetable oil, beef and pork, salt, chicken, other vegetables, potatoes, green and yellow vegetables, processed meat, etc.), 'Noodle' (positive loadings on noodle soup, Japanese, Chinese and instant noodles and pasta) and 'Bread and confectioneries' (positive loadings on sweetened buns, bread, confectioneries, savoury snacks, etc. and negative loading on alcoholic beverages). For women, factors were labelled 'Fish and vegetable' (high positive loadings on other vegetables, green and yellow vegetables, salt, potatoes, fish, etc.), 'Meat and oil' (positive loadings on beef and pork, vegetable oil, chicken and processed meat and negative loadings on fruits and pulses), 'Noodle' (same as men) and 'Bread and confectioneries' (positive loadings on bread, sweetened buns, confectioneries, fatty spreads and tea and negative loadings on rice and miso soup). The total explained variance of dietary patterns was $26.0 \%$ for men and $22.4 \%$ for women, respectively.

We divided the participants into quintiles by the factor score of each dietary pattern. Sample characteristics are presented for the lowest (Q1) and highest (Q5) quintiles of each pattern (Table 1 for men and Table 2 for women). Participants in the higher quintiles of the 'Fish and vegetable' pattern were older, whereas the opposite association was seen with the other patterns. The 'Fish and vegetable' pattern was negatively associated with smoking in both sexes and with drinking only in women. The 'Meat and oil' pattern was negatively associated with systolic blood pressure in women, but this association disappeared after adjustment for age and body weight (data not shown).

Multivariable-adjusted means for urinary $\mathrm{Na}$ and $\mathrm{K}$ excretions and Na:K across quintiles of all four dietary patterns are shown in Tables 3 (men) and 4 (women). For men, after controlling for confounding factors, higher factor score for the 'Fish and vegetable' pattern was significantly associated with higher urinary K excretion $(P$ for trend $=0.008)$ and lower urinary Na:K $(P$ for trend $=0.04)$. The mean urinary $\mathrm{K}$ excretion in the participants in the highest quintile of the 'Fish and vegetable' pattern was $5.8 \mathrm{mmol} / \mathrm{d}(227 \mathrm{mg} / \mathrm{d})$ higher than those in the lowest quintile. Urinary $\mathrm{Na}$ excretion was higher in quintiles with a higher factor score for the 'Fish and vegetable' pattern, but the relationship was not significant $(211.6 v$. $205.0 \mathrm{mmol} / \mathrm{d}(12.4 v .12 .0 \mathrm{~g} / \mathrm{d}$ as salt) in the highest $v$. the lowest quintile, respectively). Higher factor score for the 'Meat, vegetable and oil' pattern was associated with neither urinary $\mathrm{Na}$ and $\mathrm{K}$ excretions nor $\mathrm{Na}$ :K. Higher factor score for the 'Noodle' pattern was significantly associated with lower urinary $\mathrm{K}$ excretion and higher Na:K $(P$ for trend $=0.04$ and 0.02 , respectively). The mean urinary $\mathrm{K}$ excretion of participants in the highest quintile for the 'Noodle' pattern was $3.2 \mathrm{mmol} / \mathrm{d}(125 \mathrm{mg} / \mathrm{d})$ lower than those in the lowest quintile. Urinary $\mathrm{Na}$ excretion was higher in quintiles with a higher factor score for the 'Noodle' pattern, but again the relationship was not significant $(216.4 v .193 .4 \mathrm{mmol} / \mathrm{d}(12.7 v .11 .3 \mathrm{~g} / \mathrm{d}$ as salt $)$ in the highest $v$. the lowest quintile, respectively).

For women, the direction of associations was similar to that in men but the number of statistically significant associations was larger in women. Higher factor score for the 'Fish and vegetable' pattern was marginally or significantly associated with higher urinary $\mathrm{Na}$ and $\mathrm{K}$ excretions after adjustment for covariates ( $P$ for trend $=0.06$ and 0.013 , respectively). Actually, the mean $\mathrm{Na}$ and $\mathrm{K}$ excretions in the highest quintile for this pattern were $13.6 \mathrm{mmol} / \mathrm{d}(0.8 \mathrm{~g} / \mathrm{d}$ as salt $)$ and $6.3 \mathrm{mmol} / \mathrm{d}(246 \mathrm{mg} / \mathrm{d})$ higher than those in the lowest quintile, respectively. For the 'Meat and oil' pattern, lower $\mathrm{Na}$ and $\mathrm{K}$ excretions were associated with a higher factor score $(P$ for trend $=0.006$ and $<0.0001$, respectively). The mean $\mathrm{Na}$ and $\mathrm{K}$ excretions in the highest quintile for this pattern were $17.1 \mathrm{mmol} / \mathrm{d}$ $(1.0 \mathrm{~g} / \mathrm{d}$ as salt) and $9.0 \mathrm{mmol} / \mathrm{d}(352 \mathrm{mg} / \mathrm{d})$ lower than those in the lowest quintile. In addition, higher $\mathrm{Na}$ excretion was significantly associated with a higher factor score for the 'Noodle' pattern $(187.0$ v. $163.8 \mathrm{mmol} / \mathrm{d}$ $(10.9 v .9 .6 \mathrm{~g} / \mathrm{d}$ as salt) in the highest $v$. the lowest quintile, respectively) and a lower score for the Bread and confectioneries' pattern $(168.3 v .180 .6 \mathrm{mmol} / \mathrm{d}(9.8 v$. $10.6 \mathrm{~g} / \mathrm{d}$ as salt) in the highest $v$. the lowest quintile, respectively). These two patterns were not significantly related with urinary $\mathrm{K}$ excretion or Na:K.

The mean food group intake and mean and proportion of $\mathrm{Na}$ intake from each food group in the highest quintile (Q5) of each dietary pattern are shown in online supplementary material, Supplemental Table 3 (men) and Supplemental Table 4 (women), respectively. Among all dietary patterns, seasonings (salt and Japanese and Western seasonings) were the largest contributor to $\mathrm{Na}$ intake. Additionally, mean food group intake and the proportion of $\mathrm{Na}$ intake from each food group differed among the different dietary patterns.

\section{Discussion}

In the current study we identified four dietary patterns in the current Japanese diet and showed a number of 
Table 1 Sample characteristics for the lowest (Q1) and highest (Q5) quintiles of four dietary patterns identified for 353 Japanese men*

\begin{tabular}{|c|c|c|c|c|c|c|c|c|c|c|c|c|c|c|c|c|c|c|c|c|c|c|}
\hline & & & \multicolumn{5}{|c|}{ 'Fish and vegetable' } & \multicolumn{5}{|c|}{ 'Meat, vegetable and oil' } & \multicolumn{5}{|c|}{ 'Noodle' } & \multicolumn{5}{|c|}{ 'Bread and confectioneries' } \\
\hline & \multicolumn{2}{|c|}{ All $(n$ 353) } & \multicolumn{2}{|c|}{ Q1 $(n 70)$} & \multicolumn{2}{|c|}{ Q5 ( $n$ 70) } & \multirow[b]{2}{*}{$\begin{array}{c}P \\
\text { valuet }\end{array}$} & \multicolumn{2}{|c|}{ Q1 $(n 70)$} & \multicolumn{2}{|c|}{ Q5 $(n 70)$} & \multirow[b]{2}{*}{$\begin{array}{c}P \\
\text { value† }\end{array}$} & \multicolumn{2}{|c|}{ Q1 $(n 70)$} & \multicolumn{2}{|c|}{ Q5 $(n 70)$} & \multirow[b]{2}{*}{$\begin{array}{c}P \\
\text { value† }\end{array}$} & \multicolumn{2}{|c|}{ Q1 $(n 70)$} & \multicolumn{2}{|c|}{ Q5 $(n 70)$} & \multirow[b]{2}{*}{$\begin{array}{c}P \\
\text { value }\end{array}$} \\
\hline & $\begin{array}{l}\text { Mean } \\
\text { or } n\end{array}$ & $\begin{array}{l}\text { SD or } \\
\%\end{array}$ & $\begin{array}{l}\text { Mean } \\
\text { or } n\end{array}$ & $\begin{array}{c}\text { SD or } \\
\%\end{array}$ & $\begin{array}{l}\text { Mean } \\
\text { or } n\end{array}$ & $\begin{array}{c}\text { SD or } \\
\%\end{array}$ & & $\begin{array}{l}\text { Mean } \\
\text { or } n\end{array}$ & $\begin{array}{l}\text { SD or } \\
\%\end{array}$ & $\begin{array}{l}\text { Mean } \\
\text { or } n\end{array}$ & $\begin{array}{c}\text { SD or } \\
\%\end{array}$ & & $\begin{array}{l}\text { Mean } \\
\text { or } n\end{array}$ & $\begin{array}{c}\text { SD or } \\
\%\end{array}$ & $\begin{array}{l}\text { Mean } \\
\text { or } n\end{array}$ & $\begin{array}{c}\text { SD or } \\
\%\end{array}$ & & $\begin{array}{l}\text { Mean } \\
\text { or } n\end{array}$ & $\begin{array}{c}\text { SD or } \\
\%\end{array}$ & $\begin{array}{l}\text { Mean } \\
\text { or } n\end{array}$ & $\begin{array}{l}\text { SD or } \\
\%\end{array}$ & \\
\hline $\begin{array}{l}\text { Age (years), mean and SD } \\
\text { Age group (years), } n \text { and \% }\end{array}$ & $44 \cdot 2$ & $13 \cdot 7$ & 34.8 & $10 \cdot 3$ & 55.9 & $11 \cdot 2$ & $<0.0001$ & $47 \cdot 6$ & $14 \cdot 4$ & 38.5 & $11 \cdot 7$ & $<0.0001$ & $46 \cdot 2$ & $13 \cdot 2$ & $42 \cdot 3$ & 14.6 & 0.02 & $46 \cdot 2$ & $13 \cdot 8$ & $42 \cdot 3$ & $13 \cdot 3$ & 0.27 \\
\hline $20-29$ & 70 & 19.8 & 31 & 44.3 & 2 & $2 \cdot 9$ & $<0.0001$ & 15 & 21.4 & 20 & 28.6 & 0.0001 & 9 & $12 \cdot 9$ & 21 & 30.0 & 0.04 & 13 & 18.6 & 14 & 20.0 & 0.32 \\
\hline $30-39$ & 77 & 21.8 & 18 & $25 \cdot 7$ & 9 & 12.9 & & 6 & 8.6 & 19 & 27.1 & & 16 & 22.9 & 13 & 18.6 & & 9 & 12.9 & 19 & $27 \cdot 1$ & \\
\hline $40-49$ & 68 & $19 \cdot 3$ & 14 & 20.0 & 8 & 11.4 & & 16 & 22.9 & 17 & $24 \cdot 3$ & & 17 & $24 \cdot 3$ & 10 & 14.3 & & 17 & $24 \cdot 3$ & 14 & 20.0 & \\
\hline $50-59$ & 67 & 19.0 & 4 & 5.7 & 11 & $15 \cdot 7$ & & 13 & 18.6 & 9 & 12.9 & & 10 & 14.3 & 13 & 18.6 & & 15 & 21.4 & 13 & 18.6 & \\
\hline $60-69$ & 71 & 20.1 & 3 & 4.3 & 40 & 57.1 & & 20 & 28.6 & 5 & 7.1 & & 18 & $25 \cdot 7$ & 13 & 18.6 & & 16 & $22 \cdot 9$ & 10 & 14.3 & \\
\hline Body height $(\mathrm{cm})$, mean and $\mathrm{SD}$ & $170 \cdot 1$ & 5.9 & $171 \cdot 2$ & 5.8 & 168.4 & $5 \cdot 3$ & 0.003 & 169.9 & 6.5 & 169.9 & $5 \cdot 2$ & 0.60 & $169 \cdot 2$ & $5 \cdot 3$ & 169.8 & 6.4 & 0.17 & 169.7 & 5.6 & 170.5 & 4.8 & 0.51 \\
\hline Body weight $(\mathrm{kg})$, mean and SD & 68.9 & 10.9 & 69.6 & 11.2 & 67.1 & 9.7 & 0.27 & 67.7 & $9 \cdot 3$ & $70 \cdot 9$ & $12 \cdot 1$ & 0.04 & 67.8 & 10.8 & $70 \cdot 1$ & 11.4 & 0.35 & 69.2 & $10 \cdot 6$ & 71.4 & 12.6 & 0.40 \\
\hline $\mathrm{BMI}\left(\mathrm{kg} / \mathrm{m}^{2}\right)$, mean and SD & 23.8 & 3.4 & 23.7 & 3.7 & 23.6 & 3.1 & 0.90 & 23.4 & 3.0 & 24.5 & 3.9 & 0.06 & 23.7 & 3.3 & 24.3 & 3.4 & 0.69 & 24.0 & 3.1 & 24.5 & 4.0 & 0.48 \\
\hline $\mathrm{SBP}(\mathrm{mmHg})$, & 127 & 14 & 126 & 13 & 129 & 14 & 0.30 & 129 & 14 & 126 & 14 & 0.55 & 129 & 14 & 129 & 13 & 0.57 & 127 & 15 & 129 & 14 & 0.73 \\
\hline DBP $(\mathrm{mmHg})$, mean and SD & 80 & 11 & 80 & 11 & 81 & 10 & $>0.999$ & 81 & 11 & 78 & 10 & 0.52 & 81 & 11 & 81 & 11 & 0.45 & 78 & 11 & 82 & 10 & 0.25 \\
\hline PAL $($ MET $\times h)$, mean and SD & 37.8 & 5.9 & 38.9 & 6.2 & $36 \cdot 1$ & 4.8 & 0.0005 & 38.3 & $5 \cdot 8$ & 38.4 & 5.9 & 0.96 & 37.9 & 6.7 & 38.2 & 5.7 & 0.62 & 37.4 & 6.9 & 37.9 & $6 \cdot 1$ & 0.70 \\
\hline Energy $(\mathrm{kJ} / \mathrm{d})$, mean and SD & 9548 & 2205 & 9473 & 2853 & 9694 & 2146 & $>0.999$ & 9669 & 2791 & 9862 & 2113 & $>0.999$ & 9577 & 2561 & 9000 & 2109 & $>0.999$ & 9904 & 2360 & 9883 & 1954 & $>0.999$ \\
\hline \multicolumn{16}{|l|}{ Residential block, $n$ c } & 504 & $>0.999$ & 2367 & 564 & & 467 & \\
\hline Hokkaido and Tohoku & 55 & 15.6 & 13 & 18.6 & 15 & $21 \cdot 4$ & 0.12 & 18 & 25.7 & 7 & $10 \cdot 0$ & 0.0004 & 6 & 8.6 & 15 & $21 \cdot 4$ & 0.002 & 18 & $25 \cdot 7$ & 7 & $10 \cdot 0$ & 0.50 \\
\hline Kanto & 71 & 20.1 & 12 & $17 \cdot 1$ & 18 & 25.7 & & 17 & $24 \cdot 3$ & 15 & 21.4 & & 11 & $15 \cdot 7$ & 23 & 32.9 & & 10 & $14 \cdot 3$ & 18 & 25.7 & \\
\hline Hokurik & 35 & 9.9 & 6 & 8.6 & 9 & $12 \cdot 9$ & & 9 & 12.9 & 5 & 7.1 & & 10 & $14 \cdot 3$ & 7 & 10.0 & & 6 & 8.6 & 9 & $12 \cdot 9$ & \\
\hline Kinki & 56 & 15.9 & 13 & $18 \cdot 6$ & 8 & 11.4 & & 9 & 12.9 & 6 & $8 \cdot 6$ & & 15 & 21.4 & 7 & 10.0 & & 8 & 11.4 & 11 & 15.7 & \\
\hline Chug & 66 & 18.7 & 12 & $17 \cdot 1$ & 9 & 12 & & 8 & 11.4 & 17 & $24 \cdot 3$ & & 18 & $25 \cdot 7$ & 4 & 5.7 & & 8 & 11.4 & 18 & $25 \cdot 7$ & \\
\hline Kyushu and Okinaw & 70 & 19.8 & 14 & 20.0 & 11 & $15 \cdot 7$ & & 9 & $12 \cdot 9$ & 20 & 28.6 & & 10 & 14.3 & 14 & 20.0 & & 20 & 28.6 & 7 & 10.0 & \\
\hline \multicolumn{23}{|l|}{ Education, $n$ and \% } \\
\hline $\begin{array}{l}\text { High school or less and } \\
\text { other }\end{array}$ & 87 & 24.7 & 15 & 21.4 & 19 & $27 \cdot 1$ & 0.03 & 22 & 31.4 & 7 & $10 \cdot 0$ & 0.02 & 22 & 31.4 & 10 & $14 \cdot 3$ & 0.006 & 21 & 30.0 & 10 & 14.3 & 0.06 \\
\hline Some college & 100 & 28 & 33 & 47 & 1 & 14 & & 1 & 24 & 2 & 28 & & 2 & 28.6 & 17 & $24 \cdot 3$ & & $2 C$ & 28.6 & 25 & 35.7 & \\
\hline University or more & 166 & 47.0 & 22 & 31.4 & 41 & $58 \cdot 6$ & & 31 & 44.3 & 43 & 61.4 & & 28 & 40.0 & 43 & 61.4 & & 29 & 41.4 & 35 & 50.0 & \\
\hline \multicolumn{23}{|l|}{ Smoking, $n$ and \% } \\
\hline Non-smoker & 112 & 31.7 & 27 & 38.6 & 24 & $34 \cdot 3$ & 0.048 & 21 & 30.0 & 1 & $27 \cdot 1$ & 0.49 & 23 & 32.9 & 23 & 32.9 & 0.15 & 17 & $24 \cdot 3$ & 29 & 41.4 & 0.0002 \\
\hline Past smok & 115 & 32.6 & 9 & $12 \cdot 9$ & 28 & 40.0 & & 17 & $24 \cdot 3$ & 27 & 38.6 & & 29 & 41.4 & 15 & 21.4 & & 20 & 28.6 & 22 & 31.4 & \\
\hline & 126 & 35.7 & 34 & 48.6 & 18 & $25 \cdot 7$ & & 32 & 45.7 & 24 & $34 \cdot 3$ & & 18 & $25 \cdot 7$ & 32 & 45.7 & & 33 & $47 \cdot 1$ & 19 & $27 \cdot 1$ & \\
\hline Alcohol drinking, $n$ and $\%$ & & & & & & & & & & & & & & & & & & & & & & \\
\hline Current drinker & 269 & $76 \cdot 2$ & 47 & $67 \cdot 1$ & 60 & 85.7 & 0.008 & 50 & 71.4 & 55 & 78.6 & 0.48 & 54 & 77.1 & 53 & 75.7 & 0.33 & 63 & 90.0 & 36 & $51 \cdot 4$ & $<0.0001$ \\
\hline
\end{tabular}

SBP, systolic blood pressure; DBP, diastolic blood pressure; PAL, physical activity level; MET, metabolic equivalent of task.

†A linear trend test and the Mantel-Haenszel $x^{2}$ test were used for continuous and categorical variables, respectively. 
Table 2 Sample characteristics for the lowest (Q1) and highest (Q5) quintiles of four dietary patterns identified for 349 Japanese women*

\begin{tabular}{|c|c|c|c|c|c|c|c|c|c|c|c|c|c|c|c|c|c|c|c|c|c|c|}
\hline & & & \multicolumn{5}{|c|}{ 'Fish and vegetable' } & \multicolumn{5}{|c|}{ 'Meat and oil' } & \multicolumn{5}{|c|}{ 'Noodle' } & \multicolumn{5}{|c|}{ 'Bread and confectioneries' } \\
\hline & \multicolumn{2}{|c|}{ All $(n$ 349) } & \multicolumn{2}{|c|}{ Q1 ( $n$ 69) } & \multicolumn{2}{|c|}{ Q5 $(n 70) \dagger$} & \multirow[b]{2}{*}{$\begin{array}{c}P \\
\text { valueł }\end{array}$} & \multicolumn{2}{|c|}{ Q1 $(n$ 69) } & \multicolumn{2}{|c|}{ Q5 $(n 70) \dagger$} & \multirow[b]{2}{*}{$\begin{array}{c}P \\
\text { valueł }\end{array}$} & \multicolumn{2}{|c|}{ Q1 $(n$ 69) } & \multicolumn{2}{|c|}{ Q5 $(n 70) \dagger$} & \multirow[b]{2}{*}{$\begin{array}{c}P \\
\text { valueł }\end{array}$} & \multicolumn{2}{|c|}{ Q1 ( $n$ 69) } & \multicolumn{2}{|c|}{ Q5 $(n 70) \dagger$} & \multirow[b]{2}{*}{$\begin{array}{c}P \\
\text { valueł }\end{array}$} \\
\hline & $\begin{array}{l}\text { Mean } \\
\text { or } n\end{array}$ & $\begin{array}{l}\text { SD or } \\
\%\end{array}$ & $\begin{array}{l}\text { Mean } \\
\text { or } n\end{array}$ & $\begin{array}{l}\text { SD or } \\
\%\end{array}$ & $\begin{array}{l}\text { Mean } \\
\text { or } n\end{array}$ & $\begin{array}{l}\text { SD or } \\
\%\end{array}$ & & $\begin{array}{l}\text { Mean } \\
\text { or } n\end{array}$ & $\begin{array}{l}\text { SD or } \\
\%\end{array}$ & $\begin{array}{l}\text { Mean } \\
\text { or } n\end{array}$ & $\begin{array}{l}\text { SD or } \\
\%\end{array}$ & & $\begin{array}{l}\text { Mean } \\
\text { or } n\end{array}$ & $\begin{array}{l}\text { SD or } \\
\%\end{array}$ & $\begin{array}{l}\text { Mean } \\
\text { or } n\end{array}$ & $\begin{array}{l}\text { SD or } \\
\%\end{array}$ & & $\begin{array}{l}\text { Mean } \\
\text { or } n\end{array}$ & $\begin{array}{l}\text { SD or } \\
\%\end{array}$ & $\begin{array}{l}\text { Mean } \\
\text { or } n\end{array}$ & $\begin{array}{l}\text { SD or } \\
\%\end{array}$ & \\
\hline $\begin{array}{l}\text { Age (years), mean and sD } \\
\text { Age group (years), } n \text { and } \%\end{array}$ & $44 \cdot 3$ & $13 \cdot 3$ & $40 \cdot 8$ & $13 \cdot 0$ & 47.9 & $14 \cdot 3$ & 0.0001 & $52 \cdot 6$ & $12 \cdot 5$ & 38.9 & 10.8 & $<0.0001$ & 48.8 & $13 \cdot 6$ & 44.6 & 13.7 & 0.002 & $49 \cdot 1$ & $12 \cdot 7$ & 41.8 & $12 \cdot 8$ & 0.002 \\
\hline $20-29$ & 68 & 19.5 & 18 & $26 \cdot 1$ & 13 & 18.6 & 0.003 & 8 & 11.6 & 18 & $25 \cdot 7$ & $<0.0001$ & 10 & 14.5 & 15 & $21 \cdot 4$ & 0.03 & 9 & 13.0 & 17 & 24.3 & 0.002 \\
\hline $30-39$ & 70 & 20.1 & 15 & $21 \cdot 7$ & 8 & 11.4 & & 4 & 5.8 & 19 & $27 \cdot 1$ & & 9 & $13 \cdot 0$ & 9 & 12.9 & & 6 & 8.7 & 15 & 21.4 & \\
\hline $40-49$ & 76 & 21.8 & 17 & 24.6 & 13 & 18.6 & & 8 & 11.6 & 23 & 32.9 & & 12 & 17.4 & 18 & 25.7 & & 18 & $26 \cdot 1$ & 17 & 24.3 & \\
\hline $50-59$ & 68 & 19.5 & 10 & 14.5 & 16 & 22.9 & & 21 & 30.4 & 6 & 8.6 & & 14 & 20.3 & 16 & 22.9 & & 15 & 21.7 & 12 & $17 \cdot 1$ & \\
\hline $60-69$ & 67 & 19.2 & 9 & 13.0 & 20 & 28.6 & & 28 & 40.6 & 4 & 5.7 & & 24 & 34.8 & 12 & 17.1 & & 21 & 30.4 & 9 & 12.9 & \\
\hline Body height $(\mathrm{cm})$, mean and SD & $157 \cdot 4$ & 5.4 & $157 \cdot 3$ & 5.5 & 156.5 & 5.4 & 0.22 & 156.9 & 6.3 & 157.5 & 4.9 & 0.14 & 156.6 & 6.0 & $158 \cdot 1$ & $5 \cdot 3$ & 0.14 & 156.4 & 5.7 & $158 \cdot 1$ & 6.0 & 0.37 \\
\hline Body weight $(\mathrm{kg})$, mean and SD & $55 \cdot 6$ & 9.7 & 55.9 & 10.8 & $54 \cdot 6$ & 7.3 & 0.97 & 55.8 & 11.8 & $55 \cdot 2$ & 8.3 & 0.45 & $56 \cdot 1$ & $10 \cdot 8$ & 55.6 & 9.5 & 0.93 & $54 \cdot 2$ & 9.7 & $56 \cdot 3$ & 9.4 & 0.35 \\
\hline $\mathrm{BMI}\left(\mathrm{kg} / \mathrm{m}^{2}\right)$, mean and SD & 22.4 & 3.6 & 22.6 & 3.8 & 22.3 & 2.7 & 0.52 & 22.6 & $4 \cdot 2$ & $22 \cdot 2$ & 2.9 & 0.83 & $22 \cdot 9$ & 4.2 & $22 \cdot 2$ & 3.4 & 0.53 & 22.1 & 3.6 & 22.5 & $3 \cdot 2$ & 0.56 \\
\hline $\mathrm{SBP}(\mathrm{mmHg})$, mean and SD & 119 & 16 & 118 & 16 & 120 & 15 & 0.20 & 125 & 19 & 116 & 14 & 0.0003 & 120 & 17 & 122 & 15 & 0.74 & 123 & 14 & 118 & 13 & 0.09 \\
\hline DBP $(\mathrm{mmHg})$, mean and sD & 76 & 11 & 76 & 10 & 77 & 12 & 0.12 & 78 & 11 & 75 & 9 & 0.16 & 75 & 9 & 78 & 11 & 0.69 & 77 & 10 & 76 & 10 & 0.71 \\
\hline PAL $(M E T \times h)$, mean and SD & 38.4 & $6 \cdot 3$ & 38.4 & 7.0 & 39.1 & 5.4 & 0.16 & 38.5 & 6.0 & 39.3 & 7.0 & 0.98 & 39.1 & $6 \cdot 3$ & 38.0 & 5.5 & 0.53 & 38.5 & 5.7 & 37.8 & 5.9 & 0.95 \\
\hline Energy $(\mathrm{kJ} / \mathrm{d})$, mean and SD & 7598 & 1862 & 7489 & 2163 & 7719 & 1490 & 0.97 & 7590 & 1866 & 7489 & 1657 & 0.92 & 7686 & 1757 & 7627 & 1824 & 0.95 & 7326 & 1833 & 7401 & 1606 & 0.94 \\
\hline Energy $(\mathrm{kcal} / \mathrm{d})$, mean and SD & 1816 & 445 & 1790 & 517 & 1845 & 356 & 0.97 & 1814 & 446 & 1790 & 396 & 0.92 & 1837 & 420 & 1823 & 436 & 0.95 & 1751 & 438 & 1769 & 384 & 0.94 \\
\hline \multicolumn{23}{|l|}{ Residential block, $n$ and \% } \\
\hline Hokkaido and Tohoku & 46 & $13 \cdot 2$ & 13 & 18.8 & 7 & $10 \cdot 0$ & 0.14 & 12 & 17.4 & 5 & $7 \cdot 1$ & 0.0001 & 6 & 8.7 & 14 & $20 \cdot 0$ & 0.014 & 13 & 18.8 & 5 & 7.1 & 0.052 \\
\hline Kanto & 75 & 21.5 & 16 & 23.2 & 14 & 20.0 & & 24 & 34.8 & 10 & 14.3 & & 16 & $23 \cdot 2$ & 19 & 27.1 & & 13 & 18.8 & 16 & $22 \cdot 9$ & \\
\hline Hokuriku and Tokai & 34 & 9.7 & 5 & 7.2 & 5 & 7.1 & & 6 & 8.7 & 5 & 7.1 & & 4 & $5 \cdot 8$ & 6 & 8.6 & & 10 & 14.5 & 7 & $10 \cdot 0$ & \\
\hline Kinki & 57 & $16 \cdot 3$ & 14 & $20 \cdot 3$ & 10 & 14.3 & & 10 & 14.5 & 13 & $18 \cdot 6$ & & 12 & 17.4 & 6 & 8.6 & & 4 & $5 \cdot 8$ & 15 & 21.4 & \\
\hline Chugo & 71 & 20.3 & 9 & 13.0 & 18 & 25.7 & & 10 & 14.5 & 19 & 27.1 & & 18 & $26 \cdot 1$ & 14 & 20.0 & & 14 & 20.3 & 16 & 22.9 & \\
\hline Kyusyu and Okinawa & 66 & 18.9 & 12 & 17.4 & 16 & $22 \cdot 9$ & & 7 & 10.1 & 18 & $25 \cdot 7$ & & 13 & $18 \cdot 8$ & 11 & 15.7 & & 15 & 21.7 & 11 & $15 \cdot 7$ & \\
\hline \multicolumn{23}{|l|}{ Education, $n$ and \% } \\
\hline High school or less and other & 140 & 40.1 & 29 & $42 \cdot 0$ & 34 & 48.6 & 0.52 & 38 & $55 \cdot 1$ & 26 & 37.1 & 0.012 & 37 & 53.6 & 28 & $40 \cdot 0$ & 0.13 & 38 & $55 \cdot 1$ & 16 & $22 \cdot 9$ & 0.008 \\
\hline Some college & 145 & 41.6 & 27 & 39.1 & 26 & 37.1 & & 24 & 34.8 & 32 & $45 \cdot 7$ & & 26 & 37.7 & 30 & 42.9 & & 23 & 33.3 & 44 & 62.9 & \\
\hline University or more & 64 & $18 \cdot 3$ & 13 & 18.8 & 10 & 14.3 & & 7 & $10 \cdot 1$ & 12 & 17.1 & & 6 & 8.7 & 12 & 17.1 & & 8 & 11.6 & 10 & 14.3 & \\
\hline \multicolumn{23}{|l|}{ Smoking, $n$ and \% } \\
\hline Non-smoker & 269 & 77.1 & 44 & 63.8 & 61 & 87.1 & 0.003 & 57 & 82.6 & 54 & 77.1 & 0.93 & 54 & $78 \cdot 3$ & 52 & 74.3 & 0.44 & 49 & $71 \cdot 0$ & 56 & $80 \cdot 0$ & 0.37 \\
\hline Past smoker & 34 & 9.7 & 10 & 14.5 & 6 & 8.6 & & 4 & 5.8 & 7 & $10 \cdot 0$ & & 4 & 5.8 & 6 & 8.6 & & 9 & 13.0 & 7 & $10 \cdot 0$ & \\
\hline Current smoker & 46 & $13 \cdot 2$ & 15 & 21.7 & 3 & 4.3 & & 8 & 11.6 & 9 & 12.9 & & 11 & 15.9 & 12 & 17.1 & & 11 & 15.9 & 7 & 10.0 & \\
\hline Alcohol drinkin & & & & & & & & & & & & & & & & & & & & & & \\
\hline Current drinker & 190 & 54.4 & 47 & 68.1 & 31 & $44 \cdot 3$ & 0.002 & 40 & 58.0 & 39 & 55.7 & 0.93 & 33 & 47.8 & 44 & 62.9 & 0.07 & 41 & 59.4 & 34 & $48 \cdot 6$ & 0.13 \\
\hline
\end{tabular}

SBP, systolic blood pressure; DBP, diastolic blood pressure; PAL, physical activity level; MET, metabolic equivalent of task.

*The factors were standardized continuous variables, and each participant had a score for each factor.

tFor PAL, the fifth quintile (Q5) comprised sixty-nine participants.

$\ddagger A$ linear trend test and the Mantel-Haenszel $x^{2}$ test were used for continuous and categorical variables, respectively. 
Table 3 Multivariate-adjusted means and SE for urinary sodium and potassium excretion and sodium:potassium by quintile of each dietary pattern for 353 Japanese men

Quintile category of dietary pattern

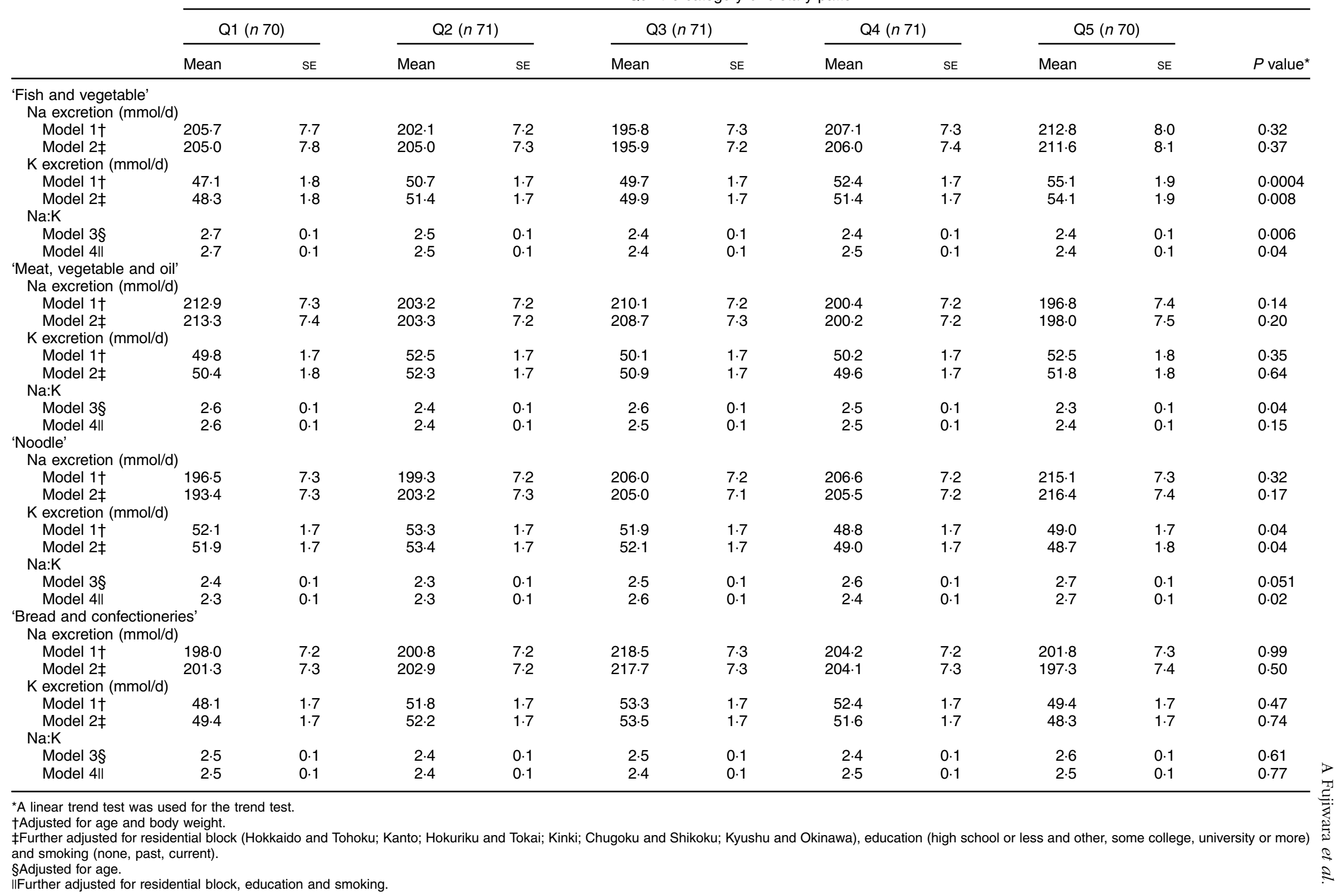


Table 4 Multivariate adjusted means and SE for urinary sodium and potassium excretion and sodium:potassium by quintile of each dietary pattern for 349 Japanese women

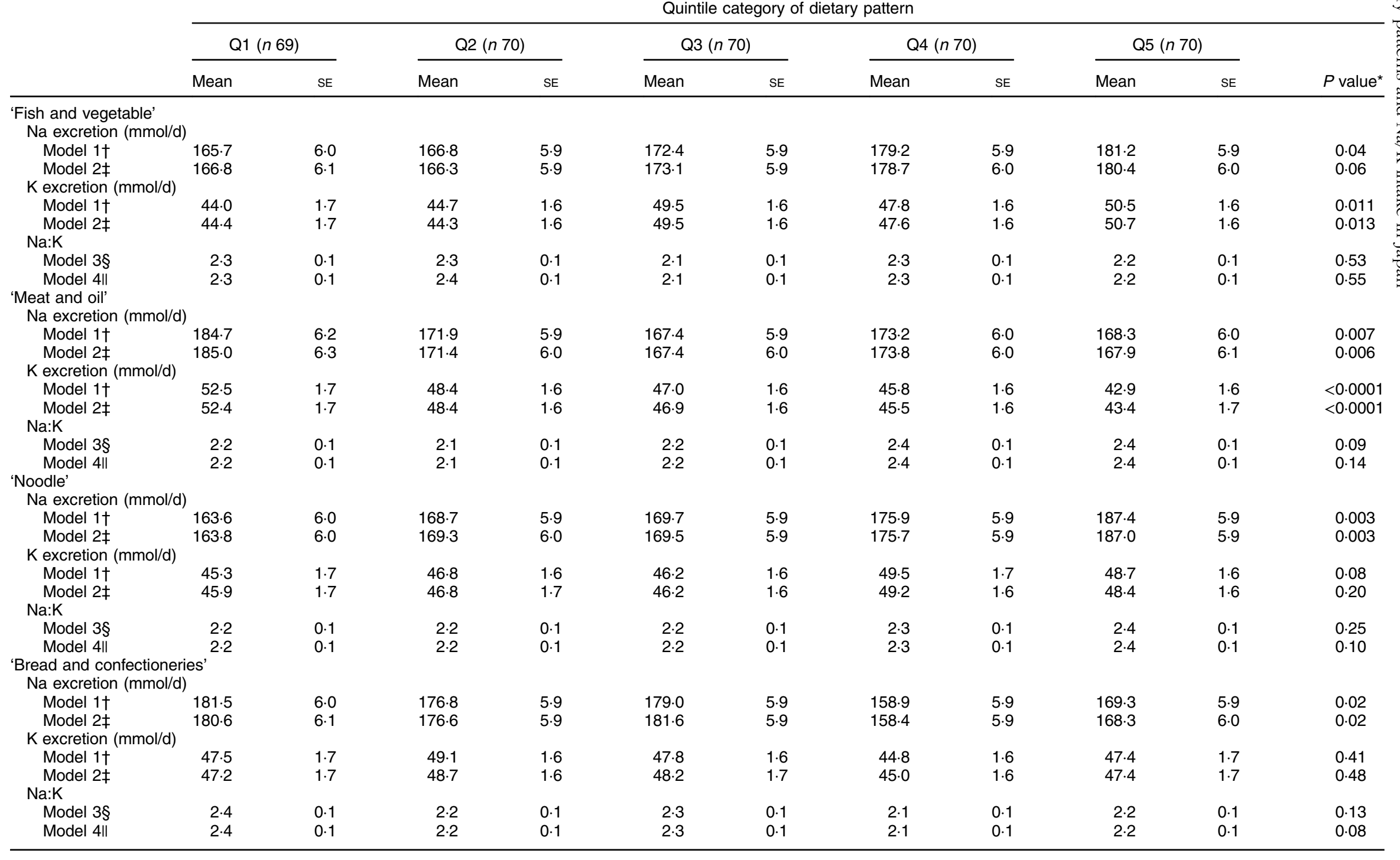

A linear trend test was used for trend test.

$\uparrow$ Adjusted for age and body weight.

FFurther adjusted for residential block (Hokkaido and Tohoku; Kanto; Hokuriku and Tokai; Kinki; Chugoku and Shikoku; Kyushu and Okinawa), education (high school or less and other, some college, university or more) and smoking (none, past, current).

$\S$ Adjusted for age.

IIFurther adjusted for residential block, education and smoking. 
associations between these patterns and urinary $\mathrm{Na}$ and $\mathrm{K}$ excretions and Na:K. To our knowledge, the present study is the first to precisely investigate the associations between dietary patterns and $\mathrm{Na}$ and $\mathrm{K}$ intakes measured by $24 \mathrm{~h}$ urine collection in a non-Western country.

The 'Fish and vegetable' pattern was similar to the 'Japanese', 'Vegetable' or 'Healthy' pattern, or 'Fish and vegetable' pattern found in previous Japanese studies ${ }^{(15-17,27)}$. These dietary patterns were characterized by high intakes of fish and vegetables and were most comparable to the so-called traditional Japanese pattern. The high $\mathrm{Na}$ intake in these patterns was due to the high intake of salty foods such as salted fish and sea products, pickled vegetables, miso soup and salt-containing seasonings, regardless of the statistical method used to identify these dietary patterns ${ }^{(15-17,27)}$. The present study reconfirmed these findings by precise $\mathrm{Na}$ intake assessment using repeated $24 \mathrm{~h}$ urinary collection. The 'Meat, vegetable and oil' pattern in men and 'Meat and oil' pattern in women were most closely comparable to the 'Western',(27) or 'Animal Food' ${ }^{(15)}$ pattern in previous Japanese studies. In the present study, the 'Meat, vegetable and oil' pattern was not associated with either $\mathrm{Na}$ or $\mathrm{K}$ intake in men. In women, the 'Meat and oil' pattern was associated with lower $\mathrm{Na}$ and $\mathrm{K}$ intakes and $\mathrm{Na}: \mathrm{K}$ was not associated with this pattern. A unique aspect of this dietary pattern was the sex difference in food intake characteristics; factor loadings on salty foods (such as fish products, pickled vegetables and miso soup), salt-containing seasonings and K-rich foods (such as fruits, vegetables, potatoes and pulses) were lower in women than in men (see online supplementary material, Supplemental Table 3). This difference might explain why this pattern was associated with lower urinary $\mathrm{Na}$ and $\mathrm{K}$ excretions in women, whereas no clear association was observed in men. Although the reason for these results is unclear, gender differences in beliefs about the healthfulness of meat might affect the characteristics of the dietary patterns. In previous research more men identified meat as the component of 'a healthy diet' than women ${ }^{(34,35)}$. Therefore, men with higher meat intake might be more healthconscious than other men and also include more fruits, vegetables, potatoes and pulses in their diet. By contrast, meat intake could not be a marker of health consciousness in women. This might explain why women with higher meat intake had stable or less intake of 'healthy' foods such as fruits or vegetables ${ }^{(36)}$. The characteristics of the 'Meat, vegetable and oil' pattern in men might be relatively similar to those of the 'Fish and vegetable' pattern, which had been considered 'Health-conscious' pattern in a previous study ${ }^{(22)}$, whereas the 'Meat and oil' pattern in women might be different from so-called 'healthy' pattern. The 'Bread and confectioneries' pattern was comparable to the 'Westernized breakfast' pattern, which was associated with a lower $\mathrm{Na}$ intake in a previous Japanese study ${ }^{(16)}$. Similarly, this pattern was not associated with either $\mathrm{Na}$ or $\mathrm{K}$ intake in men and was negatively associated with $\mathrm{Na}$ intake in women in the present study. A second unique finding in our study was the higher $\mathrm{Na}$ intake and lower (in men) or almost stable (in women) $\mathrm{K}$ intake in the 'Noodle' pattern. The reason for these results was the higher loadings of noodle and noodle soup and negative (in men) or almost null (in women) loadings for vegetables, potatoes and pulses.

The current study also showed that there was a clear association between age and dietary pattern. Older people had high score for the 'Fish and vegetables' pattern, whereas younger people had higher score for the 'Meat, vegetable and oil'/'Meat and oil', 'Noodle' and the 'Bread and confectioneries' patterns. The present study was conducted under cross-sectional design, preventing any direct mention of secular trend in dietary patterns. Nevertheless, this association between age and dietary pattern might have reflected nutrition transition ${ }^{(37)}$ in Japan and suggests that an effective salt reduction programme should consider the different contributions of particular processed foods to salt intake between generations.

Our present results differed from those of previous Western studies, in which the patterns with high loadings for bread and meat products were positively associated with high $\mathrm{Na}$ intake whereas those with high loadings for fish and vegetables were not ${ }^{(22,38)}$. This difference might be explained by the different contribution of each food group to total $\mathrm{Na}$ intake. Given that the DHQ has lower validity in estimating salt intake in men than women ${ }^{(23)}$, we first attempted to compare the contribution of each food group as an $\mathrm{Na}$ source to total $\mathrm{Na}$ intake in women. In the previous British study ${ }^{(22)}$, the proportion of $\mathrm{Na}$ intake in total women from bread or bacon/ham and sausages was $20.7 \%$ or $9.3 \%$. These values should have been higher in those who had a higher factor score for the 'Bread, spread and cheese' or 'Meat products, chips and eggs' or 'Red meat and alcohol' pattern because these dietary patterns were characterized by a higher intake of these foods. In the present study, the contribution of bread or total meat to $\mathrm{Na}$ intake in the highest quintile of the 'Bread and confectioneries' pattern or the 'Meat and oil' pattern was lower than in the British study ( $8 \cdot 1 \%$ or $4 \cdot 1 \%)$. On the contrary, the proportions of $\mathrm{Na}$ intake from fish, vegetable or sauce (the factor loadings of these foods were high in the 'Health-conscious' pattern) in the British study $^{(22)}$ were lower than their counterparts in the present study; namely, the proportions of $\mathrm{Na}$ intake from seafood, vegetables (including green and yellow, other and pickled vegetables) and Japanese and Western seasonings in the highest quintile of the 'Fish and vegetable' pattern (4.6, 4.2 and $5.3 \%$ in British women $v .6 \cdot 6,5 \cdot 8$ and $17.6 \%$ in Japanese women, respectively). Similar tendencies were seen in men. England and many other Western countries have targeted bread and/or processed foods such as meat products for salt reduction due to their major contribution 
to salt intake ${ }^{(3)}$, and this strategy has reduced the population average salt intake in England ${ }^{(39)}$. However, our present study suggests that targeting these foods for salt reduction might be less effective in Japan. Additionally, any recommendation for a dietary pattern characterized by higher fish and vegetable intakes, which was considered as 'health-conscious' in the previous study ${ }^{(22)}$ and was most comparable to the so-called traditional Japanese diet, should be done carefully because this dietary pattern is associated with high salt intake in Japan.

The major strength of the present study is its precise assessment of $\mathrm{Na}$ and $\mathrm{K}$ intakes using two $24 \mathrm{~h}$ urine collections, which is considered the gold standard ${ }^{(8)}$. In previous Japanese studies ${ }^{(15-19)}$, evaluation of $\mathrm{Na}$ and $\mathrm{K}$ intakes was conducted by dietary assessment questionnaires which were shown to include reporting error $^{(20,21)}$. In the British study, $\mathrm{Na}$ intake was also assessed by $24 \mathrm{~h}$ urine collection, but only a single collection was made ${ }^{(22)}$. It has been reported that the accuracy of a single $24 \mathrm{~h}$ urine collection was insufficient to estimate habitual $\mathrm{Na}$ and $\mathrm{K}$ intakes ${ }^{(8)}$. We also identified dietary patterns using the DHQ, in which the validity of dietary patterns was previously reported ${ }^{(27)}$. Most dietary pattern studies use dietary assessment questionnaires that have not been validated at the dietary pattern level, but rather at the food and/or nutrient intake level(s). A further strength was that we first attempted to show the Na intake for each food group and the contribution to $\mathrm{Na}$ intake to each dietary pattern. Gibson and Ashwell ${ }^{(22)}$ also presented the proportion of $\mathrm{Na}$ intake from individual food groups, but did not show the major Na source for each dietary pattern. This information is necessary to the development of effective salt reduction programmes for individual populations.

Several limitations of the present study also warrant mention. First, the participants were not randomly selected from the general Japanese population, but were volunteers, and possibly health-conscious ${ }^{(9)}$. Random sampling was not feasible because of the burden of multiple $24 \mathrm{~h}$ urine collection. Nevertheless, the participants' general characteristics were compatible with the results of national surveys ${ }^{(40,41)}$. Second, standardization of $24 \mathrm{~h}$ urine collection was difficult because the research areas were located throughout the whole of Japan. We therefore attempted to standardize the procedure as already described $^{(9)}$. Third, the factor analysis itself also had limitations, in that the procedures arose from arbitrary decisions. These decisions might have affected both the results and their interpretation. We therefore attempted to derive dietary patterns by using similar steps in the objective decision-making process as used in previous studies, namely eigenvalues, scree plots and interpretability. Finally, as mentioned above, the validity of the DHQ for $\mathrm{Na}$ intake estimation was lower in men than women (Pearson correlation coefficient was $r=0.14$ in men and $r=0.23$ in women) ${ }^{(23)}$. In the present study, the
Pearson correlation coefficient of dietary $\mathrm{Na}$ intake estimated by the DHQ (energy-adjusted by the residual method) and urinary $\mathrm{Na}$ excretion per body weight was very low in men $(r=0.03$ in men and $r=0.20$ in women, respectively; data not shown). Although the reason for this is unknown, men might report their dietary intakes less accurately than women, because men are generally less conscious about their dietary intake than women ${ }^{(42)}$. Since women are usually in charge of meal preparation in Japan, men might not comprehend the amount of seasonings used in meal preparation ${ }^{(43)}$. However, the validity of the DHQ for food group intake estimation was sufficient (median Spearman correlation coefficient was 0.44$)^{(24)}$. We therefore consider that the intake of foods in each dietary pattern was estimated precisely even in men, and that their contribution to total $\mathrm{Na}$ intake should have been measured in a similar manner to that in women.

\section{Conclusion}

We identified four dietary patterns among Japanese adults. The 'Fish and vegetable' pattern as well as the 'Noodle' pattern contributed to higher $\mathrm{Na}$ intake. The 'Fish and vegetable' pattern was simultaneously associated with higher $\mathrm{K}$ intake. Given that similar dietary patterns derived from Japan and the UK had different influences on $\mathrm{Na}$ intake, target foods for salt reduction should be set based on careful consideration of the relationships between major dietary patterns and $\mathrm{Na}$ and $\mathrm{K}$ intakes in the target population.

\section{Acknowledgements}

Acknowledgements: The authors and their colleagues thank the participants of this study and the dietitians who supported the survey in each welfare facility for their valuable contribution. Financial support: This study was financially supported by a Health and Labour Sciences Research Grant (number H23-Jyunkankitou(seishuu)ippan-001) from the Ministry of Health, Labour and Welfare, Japan. The Ministry of Health, Labour and Welfare had no role in the design, analysis or writing of this article. Conflict of interest: The authors declare that they have no conflicts of interest. Authorship: S.S. designed and directed the study. S.M. managed the study field establishment and recruitment. K.A. and K.U. collected and managed the data. K.A. assisted in manuscript preparation. A.F. carried out the statistical analyses and wrote the manuscript. Ethics of human subject participation: This study was conducted according to the guidelines laid down in the Declaration of Helsinki and all procedures involving human subjects were approved by the Ethics Committee of the University of Tokyo, Faculty of Medicine (approval number 10005, approval date 7 January 2013). 


\section{Supplementary material}

To view supplementary material for this article, please visit http://dx.doi.org/10.1017/S1368980016000641

\section{References}

1. O'Donnell M, Mente A, Rangarajan S et al. (2014) Urinary sodium and potassium excretion, mortality, and cardiovascular events. $N$ Engl J Med 371, 612-623.

2. Neal B (2007) The Effectiveness and Costs of Population Interventions to Reduce Salt Consumption. Geneva: WHO.

3. Webster J, Trieu K, Dunford E et al. (2014) Target salt 2025: a global overview of national programs to encourage the food industry to reduce salt in foods. Nutrients 6, 3274-3287.

4. He FJ \& MacGregor G (2009) A comprehensive review on salt and health and current experience of worldwide salt reduction programmes. J Hum Hypertens 23, 363-384.

5. World Health Organization (n.d.) Population sodium reduction strategies. http://www.who.int/dietphysicalactivity/ reducingsalt/en/ (accessed September 2015).

6. Intersalt Cooperative Research Group (1988) INTERSALT: an international study of electrolyte excretion and blood pressure: results for $24 \mathrm{~h}$ urinary sodium and potassium excretion. Br Med J 297, 319-328.

7. Zhou BF, Stamler J, Dennis B et al. (2003) Nutrient intakes of middle-aged men and women in China, Japan, United Kingdom, and United States in the late 1990s: the INTERMAP study. J Hum Hypertens 17, 623-630.

8. Willett W (editor) (2013) Nutritional Epidemiology, 3rd ed. New York: Oxford University Press.

9. Asakura K, Uechi K, Sasaki Y et al. (2014) Estimation of sodium and potassium intakes assessed by two $24 \mathrm{~h}$ urine collections in healthy Japanese adults: a nationwide study. Br J Nutr 112, 1195-1205.

10. World Health Organization (2012) Guideline: Sodium Intake for Adults and Children. Geneva: WHO.

11. World Health Organization (2012) Guideline: Potassium Intake for Adults and Children. Geneva: WHO.

12. Anderson CA, Appel LJ, Okuda N et al. (2010) Dietary sources of sodium in China, Japan, the United Kingdom, and the United States, women and men aged 40 to 59 years: the INTERMAP study. J Am Diet Assoc 110, 736-745.

13. Tsugane $S$ \& Sawada N (2014) The JPHC study: design and some findings on the typical Japanese diet.Jpn J Clin Oncol 44, 777-782.

14. Newby PK \& Tucker KL (2004) Empirically derived eating patterns using factor or cluster analysis: a review. Nutr Rev 62, 177-203.

15. Shimazu T, Kuriyama S, Hozawa A et al. (2007) Dietary patterns and cardiovascular disease mortality in Japan: a prospective cohort study. Int J Epidemiol 36, 600-609.

16. Akter S, Nanri A, Pham NM et al. (2013) Dietary patterns and metabolic syndrome in a Japanese working population. Nutr Metab (Lond) 10, 30.

17. Maruyama K, Iso H, Date C et al. (2013) Dietary patterns and risk of cardiovascular deaths among middle-aged Japanese: JACC Study. Nutr Metab Cardiovasc Dis 23, 519-527.

18. Okubo H, Sasaki S, Murakami K et al. (2010) Nutritional adequacy of four dietary patterns defined by cluster analysis in Japanese women aged 18-20 years. Asia Pac J Clin Nutr 19, $555-563$.

19. Okubo H, Miyake Y, Sasaki S et al. (2011) Nutritional adequacy of three dietary patterns defined by cluster analysis in 997 pregnant Japanese women: the Osaka Maternal and Child Health Study. Public Health Nutr 14, 611-621.
20. Huang Y, Van Horn L, Tinker LF et al. (2014) Measurement error corrected sodium and potassium intake estimation using 24-hour urinary excretion. Hypertension 63, 238-244.

21. Murakami K, Sasaki S, Uenishi K et al. (2012) The degree of misreporting of the energy-adjusted intake of protein, potassium, and sodium does not differ among under-, acceptable, and over-reporters of energy intake. Nutr Res 32, 741-750.

22. Gibson S \& Ashwell M (2011) Dietary patterns among British adults: compatibility with dietary guidelines for salt/ sodium, fat, saturated fat and sugars. Public Health Nutr 14, 1323-1336.

23. Sasaki S, Yanagibori R \& Amano K (1998) Validity of a selfadministered diet history questionnaire for assessment of sodium and potassium: comparison with single 24-hour urinary excretion. Jpn Circ J 62, 431-435.

24. Kobayashi S, Murakami K, Sasaki S et al. (2011) Comparison of relative validity of food group intakes estimated by comprehensive and brief-type self-administered diet history questionnaires against $16 \mathrm{~d}$ dietary records in Japanese adults. Public Health Nutr 14, 1200-1211.

25. Kobayashi S, Honda S, Murakami K et al. (2012) Both comprehensive and brief self-administered diet history questionnaires satisfactorily rank nutrient intakes in Japanese adults. J Epidemiol 22, 151-159.

26. Agency Science and Technology (2010) Standard Tables of Food Composition in Japan, 5th revision. Tokyo: National Printing Bureau (in Japanese).

27. Okubo H, Murakami K, Sasaki S et al. (2010) Relative validity of dietary patterns derived from a self-administered diet history questionnaire using factor analysis among Japanese adults. Public Health Nutr 13, 1080-1089.

28. Murakami K, Sasaki S, Takahashi Y et al. (2008) Sensitivity and specificity of published strategies using urinary creatinine to identify incomplete $24-\mathrm{h}$ urine collection. Nutrition 24, 16-22.

29. McAlister FA \& Straus SE (2001) Evidence based treatment of hypertension. Measurement of blood pressure: an evidence based review. BMJ 322, 908-911.

30. Ainsworth BE, Haskell WL, Herrmann SD et al. (2011) 2011 compendium of physical activities: a second update of codes and MET values. Med Sci Sports Exerc 43, 1575-1581.

31. Northstone K (2012) Dietary patterns: the importance of sex differences. Br J Nutr 108, 393-394.

32. Knuiman JT, Hautvast JG, van der Heyden L et al. (1986) A multi-centre study on completeness of urine collection in 11 European centres. I. Some problems with the use of creatinine and 4-aminobenzoic acid as markers of the completeness of collection. Hum Nutr Clin Nutr 40, 229-237.

33. Hishida A \& Sasaki S (2014) Dietary Reference Intakes for Japanese, 2015. Tokyo: Daiichishuppan (in Japanese).

34. Beardsworth A, Bryman A, Keil T et al. (2002) Women, men and food: the significance of gender for nutritional attitudes and choices. Br Food J 104, 470-491.

35. Pomerleau J, McKee M, Robertson A et al. (2001) Dietary beliefs in the Baltic Republics. Public Health Nutr 4, 217-225.

36. Okubo H, Sasaki S, Murakami K et al. (2011) The ratio of fish to meat in the diet is positively associated with favorable intake of food groups and nutrients among young Japanese women. Nutr Res 31, 169-177.

37. Popkin BM (2006) Global nutrition dynamics: the world is shifting rapidly toward a diet linked with noncommunicable diseases. Am J Clin Nutr 84, 289-298.

38. Schulze MB, Hoffmann K, Kroke A et al. (2001) Dietary patterns and their association with food and nutrient intake in the European Prospective Investigation into Cancer and Nutrition (EPIC)-Potsdam study. Br J Nutr 85, 363-373.

39. Sadler K, Nicholson S, Steer T et al. (2011) National Diet and Nutrition Survey - Assessment of Dietary Sodium in 
Adults (aged 19 to 64 years) in England, 2011. London: Department of Health.

40. Ministry of Education, Culture, Sports Science and Technology of Japan (2015) Tairyoku, Undo-Noryoku Chosa (Survey for Physical and Motor Fitness). http://http//www. mext.go.jp/a_menu/sports/kodomo/zencyo/1342657.html (accessed September 2015).

41. Cancer Control and Health Promotion Division, Health Service Bureau, Ministry of Health Labour and Welfare of Japan (2012) The National Health and Nutrition Survey in
Japan (in Japanese). http://www.e-stat.go.jp/SG1/estat/ GL08020101.do?_toGL08020101_\&tstatCode=000001041744 \&requestSender=dsearch (accessed September 2015).

42. Lau C, Glümer C, Toft U et al. (2008) Identification and reproducibility of dietary patterns in a Danish cohort: the Inter99 study. Br J Nutr 99, 1089-1098.

43. Statistic Bureau Ministry of Internal Affaires and Communications (2011) Survey on Time Use and Leisure Activities. http://www.stat.go.jp/english/data/shakai/ (accessed January 2016). 